\title{
COMPLICATIONS OF THE MANAGEMENT OF ACUTE RESPIRATORY FAILURE AND THEIR PREVENTION
}

\author{
by Faroque Khan. Rajnder Chitkara
}

From the Division of Pulmonary Medicine, Department of Medicine, Queens Hospital Center Affiliation, Long Island Jewish-Hillside Medical Center, Queens, New York and School of Medicine, Health Sciences Center. State University of New York at Stony Brook

DOI: http://dx.doi.org/10.5915/13-2-11934

\section{SUMMARY}

We present an analysis of the complications of the management of Acute Respiratory Failure (ARF) in 1955 patients over a tcrs ycar period at Queens Hospital Center in New York City. Stress ulcer gastric bleeding, renal failure. nosocomial infections, pulmonary embolism. cardiac arrhythmias. atclectasis, barotrauma, laryngeal and tracheal complicalions are revicwed. Based on our experience recommendations regarding the avoidance of these complications are presented.

\section{KEY WORDS:}

Respiratory Intensive Care Unit - RICU Acute Respiratory Failure - ARF

Flexible Fiberoptic Bronchoscopy - FFB

Endotracheal Tube - ETT

Positive End Expiratury Pressure - PEEP

\section{INTRODUCTION}

The Respiratory Intensive Care Unit (RICU) at Queens Hospital Center was established in May. 1968 Table I lists the total number of patients admitted and their mortality: from May, 1968 to July, 1979. During the initial three years the average yearly mortality was $32 \%$. As our experience enlarged. the mortality decreased 10 around $20 \%$. However, some complications seem to occur with regularity. In January. 1974, a prospective study of the various complications of respiratory failure was started. This paper describes our experience with the various complications of respiratory failure, along with the pertinent literature review. The studies on gastric bleeding. renal failure, coagulation disorders. atelectasis were done at different times between 1974 -

TABLE 1

RICU AT QUEENS HOSPITAL CENTER

May, 1968 to July, 1979

Total Admissions ...................... 1955

Total Intubations ................. 1370

Diagnosis

C.O.P.D.

Post Operative

Pncumonia (complicated)

Bronchial Asthma

Multiple Trauma

Tuberculosis (complicated)

Drug Overdose

Respiratory Burn

*Miscellaneous (1.5\% or less)
No. Admissions/Percent

$\begin{array}{rr}387 & (19.6) \\ 356 & (18.2) \\ 189 & (9.6) \\ 182 & (9.3) \\ 98 & (5.0) \\ 96 & (5.0) \\ 53 & (2.7) \\ 26 & (1.4) \\ 568 & (29.06)\end{array}$

Mortality \%

19

15

44

3

17

15

7

38

23

$20 \%$

Botulism

Old Polio

Pulmonary Fibrosis

Kyphoscoliosis

Cardiomyopathy

Steven Johuson Syndrome

Systemic Lupus Erythematosis
Upper Airway Obstruction

Myasthenia Gravis

CO Poisoning

Hodgkin's Disease

Tetanus

Primary Pulmonary Vascular Disease 
1979. therefore the total number of patients in each study is different. The patho-physiologic changes and treatment of respiratory failure have been reviewed elsewhere' ${ }^{2}$.

\section{GASTRIC BLEEDING}

Massive gastric bleeding due to stress ulceration has been reported from RICU: The presence of gastric acid with breakdown of the gastric mucosal barrier is necessary for the development of such stress ulcers.

From January: 74 to December. 75 we observed massive upper gastric bleeding necessitating more than 2 units of blood transfusion due to multiple gastric stress ulcers, in 40 of the 420 consecutive admissions ( $9.5 \%$ ) to the RICU. Although the overall mortality was $18 \% .25$ of the 40 patients with gastric bleeding died $(62.5 \%)^{4}$.

In July. 1976 we began an antacid neutralization protocol in which the gastric contents are aspirated and the lirst 10 to $15 \mathrm{cc}$ discarded, as this material usually represents the aspirate from the nasogastric lube and may give a falsely high $\mathrm{pH}$ level from the antacid in the nasogastric tube. The $\mathrm{pH}$ of the gastric aspirate is measured. then antacid (between $10-120 \mathrm{cc}$ ) is added to increase $\mathrm{pH}$ above 5 units. The procedure is repeated every hour, 24 hours a day, until patient is extubated and resumes a regular diet. Since January. 1978 we have been using cimetidine, an $\mathrm{H} 2$ Blocker, $30 \mathrm{mgm}$ IV every 6 hours in patients with odd numbered birthdates while patients with even numbered birthdates continue to receive hourly antacids only.

\section{Results of Gastric Neutralization}

In the antacid group only three of the one hundred and seventy-live patients had massive gastric bleeding. Thus, the incidence of bleeding was reduced from $9.5 \%$ to $1.7 \%$. These results are similar to the results of other investigators:.

In the 75 patients in the Cimetidine group, three bled massively. All three had large solitary bleeding duodenal uclers, two requiring surgical therapy. In addition. seventeen patients were admitted with respiratory failure and massive gastric bleeding. All stopped bleeding within 24 to 48 hours after starting gastric neutralization with antacids in 24 patients and Cimetidine therapy in 3 patients.

We conclude that gastric neutralization is effective in both preventing and treating massive gastric bleeding in a RICU.

\section{RENAL FAILURE}

The occurrence of renal failure during respiratory failure is associated with a mortality of up to $80 \%$. In our study of 686 consecutive patients from January, 74 10 August, 77 we identified 74 patients with renal failure. Renal failure was defined as a serum creatinine of $2 \mathrm{mgm} / \mathrm{dl}$ or more with a BUN 10 creatinine ratio of less than $2010 \mathrm{l}$, or a serum creatinine over $4 \mathrm{mg} / \mathrm{dl}$ regardless of the BUN level. The major etiological factors of renal failure were: I) Massive gastric bleeding leading to hypovolemia with shock in 18 patients $(24 \%) .2)$ Septic shock in 22 patients $(30 \%), 3)$ Aminoglycoside nephroloxicity in 9 patients (13\%).4) Cardiogenic shock in 8 patients $(11 \%)$. 5) Hypotension in 8 patients $(11 \%), 6)$ Pre-existing renal lailure in 6 patients $(7 \%), 7$ ) Miscellaneous 3 paticnts (4\%).

Whereas the overall mostality in the RICU was 17 $20 \%$. the mortality in this group of patients with renal failure was $80 \%(60 / 74)$. We do not feel the use of PEEP (24 patients), the type of respiratory failurehypercapnic or predominantly hypoxic was responsible in the evolution of renal failures. Five patients had hemodialysis and eleven had peritoneal dialysis. The mean creatinine level of all 16 patients at the start of the dialysis was $10 \mathrm{mgm} / \mathrm{d}$. Eight of the sixteen dialyzed patients survived. Of the 58 nondialyzed patients, 52 died. We fecl the early institution of dialysis in these critically-ill paticnts is helplul in improving the chances for survival.

Our conclusions from this study were: 1) Renal lailure is prevalent in the RICU, 2) The main etiological factors precipitating renal failure are gastrointestinal bleeding leading to hypovolemia and shock, sepsis, drug nephrotoxicity and hypotension. These conditions should be anticipated and avoided where possible. Once renal failure occurs. early dialysis should be seriously considered.

\section{PULMONARY EMBOLISM}

Pulmonary thromboembolic disease has been reported to be the most common pathologic process in hospitalized patients. However, because of the lack of sensitivity and specificity of clinical manifestations of pulmonary embolism, its precise diagnosis is dillicult. The problem is underscored in patients with acute respiratory failure, whereby, similar manifestations may already be present from underlying cardiopulmonary disease or from other varied complications of respiratory failure. One series reported an autopsy incidence of $27 \%$ of pulmonary embolism in 66 patients dying in RICU. half of whom were not diagnosed antemortem ${ }^{6}$. In an analysis of 100 consecutive autopsies of patients dying in our RICU, the incidence of puimonary thromboembolism was $12 \%$. Half the patients affected by the pulmonary embolism died as a result of it. This low incidence is attributed to the emphasis in our RICU placed on the prevention of pulmonary embolism by vigorous leg care and early ambulation.

It is likely that, a constant awareness, continuous clinical surveillance and, aggressive attempts to document pulmonary emboli, together with vigorous leg care, early ambulation and, possibly low dose 
heparin therapy in selected cases. may further reduce the morhidity and/or mortality from pulmonary thromboembolism in patients being managed for respiratory failure.

\section{COAGULOPATHIES}

Laboratory abuormalities of coagulation stuties consisting of minimal flucluation in prothrombin time and partial thromboplastin timc. increased fibrinolytic activity and reduced platelet count are often seen in ARF. In a prospective and retrospective study of coagulation in 26 patients with stress ulcer gastric bleeding and 120 consceutive patients with ARF over a six month period we found: 1) One or two abnormalities of coagulation studies were not uncommon $(27 \%)$. 2) A pattern of significantly abnormal coagulopathy was uncommon $(5 \%)$. 3) Generalized bleeding duc to coagulopathy was not observed. 4) Stress ulcer hemorrhage did not appear to result from a coagulopathy.

The minimal coagulation changes observed in our patients are similar to those reported and are attributed to vigorous treatment of underlying disease coupled with judicious cardiopulmonary support.

\section{CARDIAC ARRHYTHMIAS:}

Cardiac arrhythmias during ARF are intermittent and frequens. with an electrocardiographic incidence of $321047 \%{ }^{8}$. and an $89 \%$ incidence on continuous monitoring in whom $57 \%$ were severe enough 10 require treatment? Although the supraventricular arrhythmias are more frequent than ventricular arrlythmias. the prognosis of patients with the latter is much worse than the former with mortality up to $70 \% \%^{8} .9$

A combination of factors responsible for cardiac arrhythmias during ARF include hypoxemia. associated hypocapnea, metabolic abnormalities that occur during the management of ARF. associated coronary artery disease. and possibly elevated right atrial pressure.

The prevention and treatmen of cardiac arrhythmias is dependent upon 1) early recognition by continuous monitoring. 2) the correction of hypoxemia. inappropriate ventilation. metabolic disturbances and treatment of associated underlying cardiac disease.

\section{NOSOCOMIAL INFECTIONS}

Nosocomial infections are a major cause of morbidity and/or mortality in patients being treated for ARF. Impaired hosi defenses, mechanical or immune, contaminated support equipment especially reservoir nebulizers and. colonization of the respiratory tract are important predisposing factors. Nosocomial infections account for $0.5 \%$ 10 $5 \%$ of all hospitalized patients. However. the incidence is greater in critical carc units with a range between $12 \%$
$1021 \%$. With the widespread use of antibiotics, and the technological advances in medical care. the spectrum of nosocomial infections over the past three decades has changed. Currently. gram-negative bacilli including pseudomonas aeruginosa, serratia marcescens, klebsiella and enterobacter species are mainly responsiblc for nosocomial infections. Futhermore. fungal superinfections. especially with Candida species are also common. Pneumonias due to these organisms are associated with a high mortality. especially pseudomonas pneumonia", and are often eomplicated by slow resolution. cavitation and empyema.

The incidence of bacterial or fungal colonization incrases during or after antimicrobial therapy. A direct relationship secms to exist between colonization with grani-negative organisms and the development of pneumonia. In one series. colonization occurred in $45 \%$ of patients $-22 \%$ on the first day. Pneumonia developed in $25 \%$ of colonized parients compared io $3.3 \%$ of non-colonized paticntsi2.

Appropriate measures reduce the incidence of colonization and nosocomial pneumonia. A surveillance program with regular cultures of the affluent air flow. decontamination of the respiratory support equipment and sinks, meticulous care of the endotracheal or tracheostomy tube and in-dwelling catheters. reverse isolation of most susceptible hosts and. control of human carriers with frequent hand washings are the peventive measures recommended. Suggestions have been made for nebulization of antimicrobial agents into the trachea and large airways in an attempt to prevent or delay gramnegative coloniation. However. the data are inconclusive ${ }^{10}$.

\section{ATELECTASIS AND ROLE OF FLEXIBLE FIBEROPTIC BRONCHOSCOPY (F.F.B.)}

The left main bronchus (LMB) has a $45^{\circ}$ take off angle from the trachea and is smaller than the right main bronchus (RMB). Therefore, LMB is less accessible to suctioning resulting in a pooting of secretions. segmental. lobar or total atelectasis. With llexible liberoptic bronchoscopy (FFB) this problem has been greatly alleviated"3. Some complications associated with bedside FFB include: 1) development of a PEEP effect, 2) increased incidence of barotrauma. 3) decreased tidal volume and minute ventilation. 4) increased $\mathrm{PCO} 2$ and decreased $\mathrm{PaO} 2$ particularly during prolonged suctioning, 5) increased cardiac output. In order 10 minimize these complications we give $100 \%$ inspired oxygen for a few minutes before, during and a few minutes after completion of the procedure. readjust and monit or the tidal volume to overcome the small air leak which invariably develops, minimize the duration of 
suctioning, check chest x-ray after the procedure, and use a size 8.0 endotracheal tube or larger.

In a series of 448 consecutive admissions, we found $33(7.3 \%)$ with persistent unresponsive segmental and/or lobar atelectasis. After bedside FFB 26 (79\%) showed immediate significant radiologic and physiological improvement. In the patients who do not improve with $F F B$ we treat with sequential segmental and/or lobar lavage using up to $300 \mathrm{cc}$ of normal saline as lavage fluid.

\section{LARYNGEAL AND TRACHEAL COMPLICA- TIONS}

The problems resulting from the use of an endotracheal tube (ETT) can be immediate or delayed. Immediate problems include malpositioning of the ETT. trauma to the tongue, epiglott is, larynx, trachea with secondary inlection at the site of the trauma ${ }^{14}$.

\section{LARYNGEAL COMPLICATIONS}

Laryngeal complications consist of arytenoid damage. vocal cord immobility. subglotic granulation leading to stenosis and upper airway obsiruction. In a study of 65 orally intubated patients we found three female paticnts with bilateral vocal cord immobility and subglottic stenosis. Two required permanent tracheostomy and one had multiple surgical procedures over a two-year period including attempted dilatation of subglottic stenosis. placement of a stent and eventual excision of part of the larynx and anastomosis of the tracliea to the larynx with an excellent lunctional recovery.

From our study we concluded that laryngeal damage can be minimized if (a) proper size ETT is selected. particularly in women as they have a smaller larynx than men, (b) the ETT is lirmly anchored and movement of patient's head mininized, (c) immediate post extubation hoarseness is the rule but improves with time. We leave oral ETT for up to three weeks.

\section{TRACHEAL COMPLICATIONS}

The tracheal complications predominantly occur at the site of the culf and at the stoma of the tracheostomy. The tracheal stomal lesions arc unrelated to previous use of artilicial ventilation and fibrosis is characteristically localized anteriorly, stomal lesions may be caused by too large size stoma and tube, excessive tube movernent. and local infection. Stomal trauma can be minimized by using a swivel system of conneciors at the tracheostomy.

Tracheal cuff complications are caused by the high intracuff pressures which impair capillary circulation. cause ischemic necrosis, exposure of tracheal cartilage leading 10 tracheoesophageal fistula (TEF). tracheomalacia or tracheal stenosis. Amongst 1370 intubated patients, we have seen 5 patients with tracheal stenoses, 4 patients with TEF and 2 with tracheomalacia, an overall incidence of less than $1 \%$ (11/1370). We also found an excellent correlation between an enlarging tracheal cuff size on chest roentgenogram and progressive tracheal damage. A ratio of cuff size to trachea size (C/T) over 1.5 is a reliable early predictor of serious early tracheal damagels. Tracheal damage can be minimized by (a) the use of only high compliance cuffs, (b) the maintenance of culf pressure less than $30 \mathrm{~mm} / \mathrm{Hg}$. (c) the use of minimal air leak technique. (d) monitoring C/T ratio.

\section{PULMONARY BAROTRAUMA}

Pulmonary barotrauma (i.e.. pneumothorax. pneumomediastinum, subcutaneous emphysema or pneumoperitoneum) is a recognized complication in patients on assisted ventilation. Large tidal volumes. high peak inspiratory pressures, high levels of PEEP and the diseased state of the underlying lung are important predisposing lactors in the development of pulmonary barolrauma. The reported incidence of pulmonary barotrauma has varied from $40 \% !^{\text {IK }}$ to as low as $0.5 \%$. The low incidence has been speculated in part to be due to refinement of ventilatory practices. effective sedation and/or relaxation of patients to facilitate mechanical ventilation and, the use of internittent mandatory vemtilation.

The diagnosis of pulmonary barotrauma is based on clinical suspicion. radiological cvaluation and pulmonary function alterations. Alterations in static compliance curves i.e. large increase in pressurc for a small gain in volume ${ }^{17}$ and sudden unexplained rapid elevation of pulmonary artery pressure are important indications of pulmonary barotrauma. Pncumoperitoneum due 10 pulmonary barotrauma is difficult to differentiate from pneumoperitoneum caused by a perforated abdominal viscus.

The prevention of pulmonary barotrauma lies in the judicious evaluation of the pulmonary function and hemodynamic alterations in a patient receiving assisted ventilation ${ }^{1 ?}$.

\section{MISCELLANEOLS COMPIICATIONS}

Some of the complications reported in the literature, but not observed with any regula rity in our series include (a) gastric distension (b) intensive care delirium (c) pulmonary water retention (d) abnormalities of liver function and jaundice (e) pulmonary arteriovenous fistula (f) complications resulting from malfunctioning of the ventilator, machine failure, alarm failure, inadequate humidification, nebulization ${ }^{14}$.

In conclusion during management of ARF, scveral complications involving multiple organs are frequently encountered. Many of these complications can be avoided by judicious prophylaxis as outlined 
above. We find evaluation of serial chest roentgenograms vital for the early detection of barotrauma, impending tracheal damage by evaluating cuff/trachea ratio, recognizing nosocomial infections, atelectasis and for evaluation of the SwanzGanz Catheter position. Effective modern

\section{FIGURE 1}

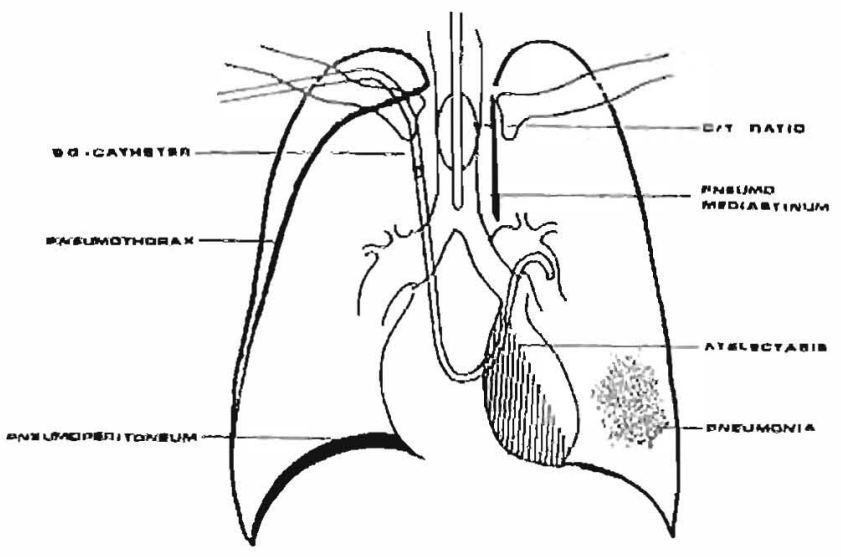

\section{REFERENCES}

1. Pontoppidan. H., Geffin, B., and Lowenstein. E: Acute Respiratory Failure in the Adult. N. Engl. $J$. Med. 287: 690-698, 743-752. 799-806. 1972.

2. Serilf, NS. Khan, F., Lazo, B.: Acute Respiratory Failure - A Review of Pathophysiology and Management. Med. Cin. North America 57: 15391550. 1973.

3. Hasting, PR. Skillman, JJ. Bushncll, LS. Silen. W.: Antacid titration in the prevention of acute gastrointestinal bleeding. N. Engl. J. Med. 298: 1041-1045. 1978.

4. Khan. F. Seriff, NS.: Stress ulcer bleeding as a major cause of death in patients undergoing treatment for acute respiratory failure. Chest 70 : 430, 1976 (Abst.)

5. Kraman, S., Khan, F., Patcl, S. Serifr, NS: Renal failure in the respiratory inensive care unit. Critical Care Medicine 7: 263-266, 1979.

6. Neuhas, A., Bentz, RR, and Weg, JC: Pulmonary embolism in respiratory failure. Chest 73: 440465, 1978.

7. Douglas, ME. Downs. JB, Dannemiller, FJ, and Hodges, MJ: Acute respiratory failure and intravascular coagulation. Surg. Gynec. Obst. 143: 555-560, 1976.

8. Hudson, LD, Jurt, TL, Petty, TL. and Genton, E: Arrhythmias associated with acute respiratory failure in patients with chronic airway obstruction. Chest 63: 661-665, 1973.

9. Holford. FD, and Mithoefer, JC: Cardiac arrhythmias in hospitalized patients with chronic management of ARF requires a multidisciplinary approach involving trained and motivated nurses. therapists and physicians. As the experience of these personnel increases, the mortality from these complications decreases with esulting increased survival.

This drawing demonstrates the importance of chest roentgenogram in localizing the position of ETT.S.G. Catheter, calculating $\mathrm{C} / \mathrm{T}$ ratio, and recognizing the complications of atelectasis, pneumonia and barotrauma.

obstructive pulmonary disease. Am. Rev. Resp. Dis. 108: 879-885. 1973.

10. Reinarz. JA: Nosocomia] infections. Clinical Symposia 30: 1-32, 1978.

11. Stevens, RM, Teres, D, Skillman; JJ and Feingold, DS: Pneumonia in an intensive care unit. A 30 month experience. Arch. Int. Med. 134: 106-JII. 1974.

12. Johanson, WG, Pierce, AK, Sanford. JP, and Thomas. GE: Nosocomial respiratory infections with gram-negative bacilli. The significance of colonization of respiratory tract. Ann. Int. Med. 77: 701-706, 1972.

13. Barrett, CR, Flexible fiberoptic bronchoscopy in the critically-ill patient. Chest 73: 746-749, 1978 (Suppl.)

14. Zwillich, CCW. Pierson, DJ, Creagh, CE. Sutton, FD. Schalz. E. and Petty. TL: Complications of assisted ventilation. Am. J. Med. 57: 161-170, 1974.

15. Khan, F., Reddy, NC: Enlarging intra-tracheal cuff diameter. A quantitative roentgen study of its value in the early prediction of serious tracheal damage. Ann. of Thoracic Surgery 24: 49-53, 1977.

16. Bone. RC, Francis. $\mathrm{PB}$ and Pierce. AK: Pulmonary barotrauma complicating positive end-cxpiratory pressure. Am. Rev. Resp. Dis. 111: 921.1975.

17. Culler, DJ and Caldera, DL: The incidence of ventilator induced pulmonary barotrauma in critically-ill patients. Anesth. 50: 185-190, 1979. 